\section{Angiosarcoma of liver associated with phenelzine}

Angiosarcoma of the liver is extremely rare. ${ }^{1}$ It has been associated with thorium dioxide, organic arsenic, and vinyl chloride monomer. ${ }^{2}$ Phenelzine (phenethylhydrazine; Nardil), a monoamine oxidase inhibitor, causes angiosarcoma of the liver in mice. ${ }^{3}$ We describe a woman who developed angiosarcoma while taking phenelzine.

\section{Case report}

A 64-year-old woman admitted for investigation of anaemia gave a fourmonth history of malaise, bruising tendency, and cough productive of small blood clots. She had been taking phenelzine for at least six years. The initial dose was $45 \mathrm{mg}$ daily, which was reduced to $15 \mathrm{mg}$ daily after three years. Diazepam 5 or $10 \mathrm{mg}$ occasionally was the only other regular medication. There was no history of exposure to thorium dioxide, arsenic, or vinyl chloride. Examination showed pallor, generalised wasting, and several arge bruises. The liver was enlarged and palpable. Full blood count showed haemoglobin concentration $7.8 \mathrm{~g} / \mathrm{dl}$, white cell count $7 \times 10^{9} / 1\left(7000 / \mathrm{mm}^{3}\right)$, platelet count $155 \times 10^{9} / 1\left(155000 / \mathrm{mm}^{3}\right)$, and reticulocytes $6.5 \%$. Blood film showed fragmentation of red cells. Prothrombin time, thrombin clotting time, and activated partial thromboplastin time were all prolonged. Concentration of fibrin degradation products (FDP) was $160 \mathrm{mg} / 1$. Moderate haematuria was present. Urea and electrolyte concentrations, initial liver function tests, serum $\alpha$-fetoprotein value, and bone marrow appearances were normal.

The haematological findings suggested mild chronic disseminated intravascular coagulation (DIC). The haematuria and haemoptysis were ascribed to this process after exclusion of other causes. Subsequent platelet counts ranged between 20 and $100 \times 10^{9} / 1$, and the raised titre of FDP persisted. Isotope liver scan showed multiple areas of decreased uptake, and computerised axial tomography of the liver confirmed areas of abnormal texture. In the lateral epicondyle of the right humerus there was an osteolytic area suggestive of metastatic disease. Results of barium meal and excretion urography were normal. Laparoscopy of the liver surface showed multiple umbilicated nodules up to $2 \mathrm{~cm}$ diameter, unlike cirrhosis or metastatic carcinoma. Laparoscopic needle biopsies disclosed normal liver tissue with focal areas of bile-duct proliferation with large pleomorphic cells suggestive of malignancy. At laparotomy numerous haemorrhagic nodules were seen on the liver and parietal peritoneum overlying the right lobe. These were sampled for biopsy. Histologically the liver showed distorted sinusoids lined by malignant cells adjacent to the focal areas of bile-duct proliferation (see figure). There was no evidence of cirrhosis. The peritoneal nodules comprised blood-filled spaces lined by malignant endothelial cells with pleomorphic nuclei. These changes were considered to be diagnostic of angiosarcoma.

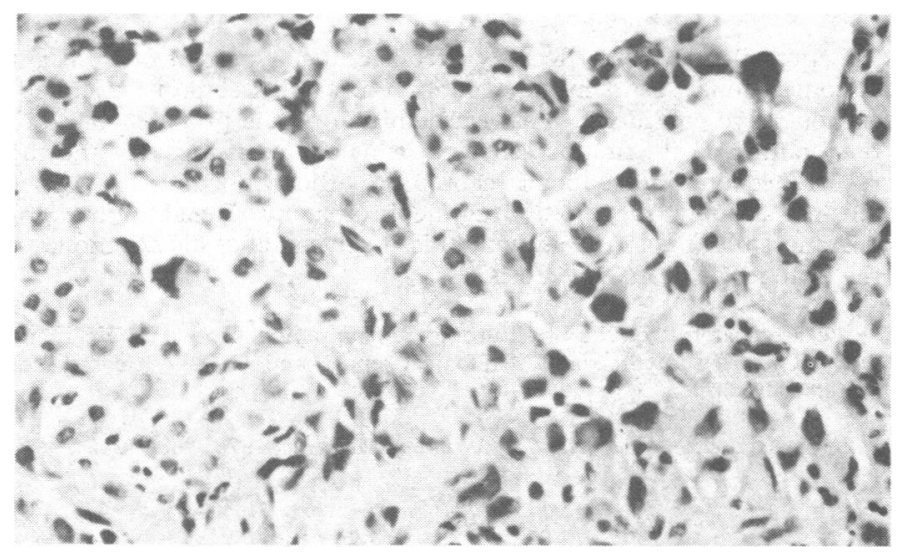

Liver biopsy specimen showing distorted sinusoids lined by malignant cells. $\mathrm{H}$ and $\mathrm{E} \times 840$ (original magnification).

The patient recovered from laparotomy and the haematuria and haemoptysis lessened. Gross bloodstained ascites developed, however, which required drainage. She died at home five months after presentation.

\section{Comment}

In animals substituted hydrazine derivatives induce a variety of tumours, including tumours of blood vessels. ${ }^{4}$ Phenelzine given to female Swiss mice significantly increased the incidence of angiosarcoma at various sites, including the liver. ${ }^{3}$ Hence the angiosarcoma in our patient may have been related to phenelzine. Although such an association in a patient has not been recorded before, this may represent failure in documenting drug history.

The presenting features of this case were probably manifestations of chronic DIC, which is associated with liver angiosarcoma. ${ }^{2}$ This process may have contributed to the bloodstained ascites. Naked-eye appearances of the liver were not diagnostic at laparoscopy or laparotomy. Primary liver tumour was diagnosed by multiple biopsy at laparotomy. We cannot be certain whether the peritoneal angiosarcomatous lesions and the lesion in the right humerus were metastases from a primary liver tumour or represented multifocal tumour growth, which is true in experimental animals. ${ }^{34}$

We suggest that inquiry about hydrazine compounds-for example, phenelzine, isoniazid, and procarbazine-should be made in future cases of angiosarcoma of the liver.

We thank Professor P J Scheuer, Royal Free Hospital Medical School, for reviewing the histology; and Dr H McNulty, Regional Drug Information Service, Bristol Royal Infirmary.

1 Baxter, P J, et al, British Medical fournal, 1978, 2, 919.

${ }^{2}$ Ishak, K G, in Hepatocellular Carcinoma, ed K Okuda and R L Peters, p 247. New York, Wiley, 1976

${ }^{3}$ Toth, B, Cancer Research, 1976, 36, 917.

${ }^{4}$ Toth, B, Cancer Research, 1975, 35, 3693.

(Accepted 2 May 1979)

Bristol Royal Infirmary, Bristol BS2 8HW

$T$ K DANESHMEND, $\mathrm{MB}$, CHB, senior house officer in haematology

G L SCOTT, MD, FRCP, consultant haematologist

J W B BRADFIELD, PHD, MRCPATH, consultant senior lecturer in histopathology

\section{Multiple lipomas in pregnancy}

Lipomas are benign tumours of adult fat cells. We report a case in which multiple lipomas first appeared during pregnancy.

\section{Case report}

The patient, aged 31, was in her second pregnancy. Her first pregnancy, in 1975, had ended in spontaneous abortion at 12 weeks. She had stopped taking a combined oral contraceptive in 1974 after two years' use. Her periods had remained irregular ever since.

She was seen first at the antenatal clinic when 20 weeks pregnant. She was of normal build, with weight $53.2 \mathrm{~kg}$ and height $156 \mathrm{~cm}$. Physical examination showed no abnormality and the pregnancy was continuing normally, the uterine size being as expected from the duration of amenorrhoea. At her next visit at 28 weeks (care being shared with her general practitioner) she mentioned isolated, soft, painful subcutaneous swellings on both forearms. These were about $2 \mathrm{~cm}$ diameter and had been present for three weeks. Later, a further six swellings on the anterior aspects of her thighs became palpable. The swellings continued to enlarge slowly throughout the rest of her pregnancy, the largest, on her left forearm, reaching $3 \mathrm{~cm}$ diameter. Biopsy of a swelling on her right forearm showed the histological features of a simple lipoma. There was no vascular proliferation to suggest angiolipoma.

The pregnancy was otherwise normal: she gained $10 \mathrm{~kg}$. She was delivered at 42 weeks by forceps of a healthy boy weighing $3400 \mathrm{~g}$. In the immediate puerperium the lipomas became less and at the postnatal check six weeks later all but a swelling $0.5 \mathrm{~cm}$ diameter on her left forearm had disappeared. No lumps on her thighs could be seen or felt. She was breast-feeding and had begun an oral contraceptive containing only progesterone. So far as she knew none of her relatives had multiple lipomas.

\section{Comment}

Lipomas are slow-growing, benign tumours of adipose tissue. Multiple tender lesions, especially if there is a family history, are characteristic of angiolipomas. ${ }^{1-3}$ Though her lipomas were tender, she had no family history, and histopathological findings were not consistent with angiolipomas.

Lipomas are common, but this is apparently the first report of multiple lipomas appearing in pregnancy and regressing in the puerperium. Possible explanations include: $(a)$ that the hormonal 